\title{
RE-DISCOVERING AESTHETICS
}

FRANCIS HALSALL, ART HISTORY

LIMERICK INSTITUTE OF TECHNOLOGY/UNIVERSITY COLLEGE CORK

JULIA JANSEN, PHILOSOPHY

UNIVERSITY COLLEGE CORK

TONY O'CONNOR, PHILOSOPHY

UNIVERSITY COLLEGE CORK

The beginning of the $21^{\text {st }}$ century has seen the renewed use of aesthetics as a critical and interpretive method within various discursive spheres. Particularly, and unsurprisingly, this move has been most pronounced in the discursive systems of philosophy and the artworld. It is to this more specific re-discovery that the authors in this journal address their arguments.

The theme of this collection of articles, then, is the perceived 'Aesthetic Turn' in philosophical and critical encounters with works of art and their relative histories. It seems that after a time in which theories and histories of art focused on logical and ontological questioning or political, social and empirical interpretations, aesthetics is making a return. At the same time that aesthetics is proving to be interesting again for philosophers the artworld too is 're-discovering' its potential. ${ }^{1}$

\footnotetext{
1 The impetus for this issue was the Re-Discovering Aesthetics conference, organised by the authors at University College Cork, July 2004. The rationale behind the conference was to instigate a discussion that questioned the uses and meaning of aesthetics amongst philosophers, art-historians and those connected with
} 
Yet despite the present interest in aesthetics, we have found that our attempts to curate, document and think through its manifestations have not revealed a clear and univocal understanding of aesthetics. However, we find it important to observe the diversity of shapes that aesthetics has taken on. It is our contention that the failure to find a comprehensive definition is a function of the different means by which aesthetics is understood and applied. As Dominic Paterson observes in his article, the term 'aesthetics' carries a considerable and important ambiguity that can refer both to its formal definitions and applications within discursive practice. According to Paterson, this is one of the most interesting aspects about aesthetics. This view suggests that its efficacy lies precisely in the fluidity of its meaning, which lends it the sort of broad appeal demonstrated by its recent cross-disciplinary rediscovery. On the other hand, however, it seems that without a further concretisation and contextualisation the mere statement of its peculiar fluidity runs a serious risk: Aesthetics might just evaporate and become the arbitrary placeholder for non-rigorous reflection or uncritical value judgment that it has been considered by some all along.

In the light of these considerations we have begun an exploration-from a perspective that attempts to reflect the concerns of philosophy as well as art history-of different takes on aesthetics' meanings, uses, merits and disadvantages. We hope that from such a perspective something of the general shape of the recent 'aesthetic turn' might come into view.

Unlike previous debates in aesthetics, which—as Daniel Davies points out in his article —are often caricatured as standing in opposition to historio- and socio-critical investigations, the most interesting current discussions (in our view) seem to have at least one concern in common: they attempt to engage in an aesthetic discourse that is sensitive to the specifically historical and social nature of the objects of (art-) experience; of the observations and interpretations of those objects and of the theories that we construct in relation to them. Despite the variety of backgrounds, 
methods, and views reflected in this issue of the Postgraduate Journal of Aesthetics, this concern for historical specificity makes itself felt (either explicitly or implicitly) in all the articles collected here.

What follows below is a more detailed report on ongoing debates in aesthetics; albeit one that is shaped by our professional commitments to philosophy and art history.

Within the artworld renewed interest in aesthetics has germinated in, broadly speaking, three different areas. These are art-making and its two associated systems of contextualisation, namely curatorial practice and writing on art.

In a recent (October, 2004) issue of Art Monthly, Mark Wilsher reflects upon the ongoing debate about aesthetics and artistic practice that has taken place in the journal over the past year. ${ }^{2}$ He observes that aesthetics is returning in a 'surreptitious rather than overt form' — and 'that many artists today are finding a refuge in the idea of beauty is beyond doubt. ${ }^{\prime 3}$ Just one example of this alleged 'rediscovery of beauty' is the installation artist Olafur Eliasson (who recently filled the space of Tate Modern with his Weather Project ${ }^{4}$ ). Eliasson creates spectacular artworks, which satiate the social appetite for spectacle but arguably lack the institutional critique demonstrated by works of art from which they take some of their cues.

There are specific historical reasons for this 'aesthetic appetite'. They emerge from the tendency (inherited from the modernist avant-garde) for generations of artists and critics to attempt a clear differentiation from the preceding artistic paradigm. Currently, this attempt at differentiation is informed by the perceived move away from the 'postmodern era' (itself a problematic concept) of the closing decades of the $20^{\text {th }}$ century. It is no mistake that Hal Foster called his collection of

\footnotetext{
${ }^{2}$ See also J.J. Charlesworth, 'The Dysfunction of Criticism,' in Art Monthly, (Sept., 2003, no. 269) 1-4; Dave Beech, 'The Art of the Encounter', in Art Monthly, (July-August, 2004, no. 278) 46; Mark Godfrey, 'Anri Sala,' in Art Monthly, (July-Aug., 2004, no. 278) 18-20; J.J. Charlesworth, 'Art and Beauty,' Art Monthly, (September, 2004, no. 279) 7-10.

${ }^{3}$ Mark Wilsher, 'Judgement Call,' in Art Monthly, (October, 2004, no. 280) 7-10.

4 Tate Modern, 16 October 2003 - 21 March 2004; see

http://www.tate.org.uk/modern/exhibitions/eliasson/understanding.htm
} 
essays on postmodern culture, 'The Anti-Aesthetic'. ${ }^{5}$ By doing so he demonstrated that what was at stake in the rejection of modernism was the enacting of an incredulity toward the autonomous aesthetic of unique works of art. Thus, within art discourse, the 're-discovery of aesthetics' can reflect a generational desire to establish a generationally specific working praxis.

Institutional responses to such art practice, couched in aesthetic terms, are exemplified in the critical practice of the French curator Nicolas Bourriaud and his concept of 'relational aesthetics.' His Relational Aesthetics (Engl. 2002) represents an attempt to engage with artistic practice since the 1990's in terms of its move into: 'the realm of human interactions and its social context, rather than the assertion of an independent and private symbolic space. ${ }^{7}$ And yet, Bourriaud conceives of such human interactions and their contexts in specifically aesthetic terms.

In art historical writing the recent return to aesthetics can be understood, as it was in relation to artistic practice, as being specific to a particular generation of practioners responding to their predecessors and their current situation in an historically specific mode. For the writing of art history the turn to aesthetics might represent a means by which the discipline re-inscribes its discursive borders and brings its focus back to particular objects and their histories. This is, in part, a response to the institutional threats that emerged in the 1970s and 80s. During that time it seemed the multiple perspectives of 'other' systems (such as Marxism, Psycho-analysis, Semiotics and so forth) threatened to transform art history into something else: a New Art History perhaps, or Visual Culture Studies. ${ }^{8}$ As the art historians Michael Ann Holly and Keith Moxey state in the introduction to Art History, Aesthetics, Visual Studies, amongst the key questions art history must ask of itself in the $21^{\text {st }}$ century are those which seek to locate its relationship to aesthetics:

To what extent has the history of art been indebted to aesthetic theory, from its foundations through its

\footnotetext{
${ }^{5}$ Foster, Hal, (ed.), The Anti-Aesthetic: Essays on Postmodern Culture, (The New Press, 1998).

${ }^{6}$ Bourriaud's Esthétique Rélational (1997) was published in English as Relational Aesthetics, (Dijon: Les Presses du Réel, 2002).

7 Nicolas Bourriaud, Relational Aesthetics, (Dijon: Les Presses du Réel, 2002) 14.

${ }^{8}$ Holly \& Moxey, (eds.) Art History, Aesthetics, Visual Studies, (Sterling and Francine Clark Art Institute, 2002); Elkins (ed.), Art History vs. Aesthetics, (Routledge/UCC Press - Forthcoming, 2005); Art History, 'Special Issue: Art History Visual Culture,' (Vol. 27, no. 4, September, 2004) see especially the articles by Deborah Cherry and Peter Osborne; Patricia Phillips, 'Aesthetic Practices,' in Art Journal, (Vol. 63, no.1, Spring 2004) 3 .
} 
twentieth century practice? What are the dominant aesthetic foundations underlying art historical investigation? How have these assumptions been challenged by visual studies? Are questions of quality, form, content, meaning or spectatorship to be considered culturally specific or universally resonant? Where do ideas about the aesthetic begin and end, both in the academy and in the museum? Can we still define the parameters of what should properly constitute the objects of the history of art? ${ }^{9}$

In all three examples above the move to aesthetics has proved controversial. It has been the focus of much criticism, which often focuses on the place aesthetics might play in the de-contextualising or de-politicization of art and its reception. An example of such critique is found in the discussion of Bourriaud's work in the current issue of October, in which Claire Bishop questions the utopian need in Bourriaud's theory for a 'unified subject as a pre-requisite for community-as-togetherness,' as unrealistic given the 'divided and incomplete subject of today. ${ }^{10}$ This is a theme also visited by John McAleer and Dominic Paterson who, in this journal, both suggest that aesthetics can be understood at one and the same time as functioning in the service of a utopian desire for communicability and intersubjectivity, whilst at the same time undermining that utopianism. The crucial moment occurs at the point at which the aesthetic mode of reflection subsumes the social under a totalizing and universalizing system of aestheticised value. The danger in such value, it would seem, is that it might obscure and negate political, social and ethical agency and difference. This is to say that we should be wary that the inter-subjectivity which the aesthetic promises does not become something to impose on others. In short, that it does not become the means by which to enforce a dominant cultural form. ${ }^{11}$ We need to be mindful of the implications of re-discovering aesthetics. And exercise our judgment.

III

Within philosophy it seems plausible to hold that, since the condemnation of aesthetics as dreary

\footnotetext{
${ }^{9}$ Holly \& Moxey, (eds.) Art History, Aesthetics, Visual Studies, (Sterling and Francine Clark Art Institute, 2002) vii.

${ }^{10}$ Claire Bishop, 'Antagonism and Relational Aesthetics,' October, (110, Fall 2004) 51-79. The current status of aesthetics in art discourse is also discussed in the articles by Hal Foster and interview by George Baker with the artist Pierre Huyghe in the same issue.

${ }^{11}$ Krauss, R., 'Using Language to do Business as Usual,' in Norman Bryson, Michael Ann Holly and Keith Moxey, (eds.), Visual Theory: Painting and Interpretation, (New York: Harper Collins, 1991) 79-94.
} 
by John Passmore in the 1950's, conventional aesthetics has remained conservative, even defensive to such critique. For example, in contrast to Dickie's institutional theory, which introduces an anthropological or sociological dimension to aesthetics, Arthur Danto links aesthetics to what he calls 'pure philosophy' by identifying the questions which philosophy should ask of artworks as 'ontological.' As Julie Kuhlken argues in her article, Danto's philosophy of art is far from being a repudiation of aesthetics. In fact, he holds that despite the so-called 'end of art', there is 'something indelible' about artworks, which it is the task of aesthetics to explain.

On the other hand, in the continental European tradition of late phenomenology (MerleauPonty), hermeneutics (Heidegger and Gadamer), post-structuralism (Derrida and Foucault) and post-modernism (Lyotard, Deleuze and Agamben, etc.), the fundamental challenge to aesthetics is that it should take much more seriously the traditional philosophical views of art and the aesthetic (from the pre-Socratics to Hegel), either by creatively reinterpreting them or by challenging them.

Despite major differences between them, philosophers from so-called 'analytic' as well as socalled 'continental' backgrounds tend to agree that changing historical circumstances and changed artistic media have necessitated differences in the way art and the aesthetic are perceived and interpreted. This, in turn, has lead to further agreements and disagreements about the role of aesthetics and its links with philosophy, art history, artworks, concepts of beauty, theories of perception and so forth.

At the heart of these debated lies a central difficulty that any turn to aesthetics, at this point in time, must acknowledge. This difficulty concerns the question of whether the various theorists are prepared to extend to a theoretical configuration of aesthetics the pluralism that is acknowledged in the variety and kinds of artworks that have proliferated throughout the last 100 years. And herein lies a central challenge for aesthetics at the beginning of the 21 st century. It may be contended that henceforth all attempts to identify in canonical terms the nature or preconditions of aesthetics, art, beauty etc., come under challenge from perspectives influenced by the specifics of historical conditions, and in particular those of art. Maria Leon Alcaraz' article in this journal provides a contemporary attempt at bridging the ontological concerns of the analytic and pragmatist traditions with a sensitivity to cultural, historical, social standpoints. She shows that our analysis of the aesthetic properties or qualities of art works must stand in relation to the very 
conditions under which we make aesthetic judgments and interpret art works. Daniel Davies proposal of an 'aesthetics of agency' extends this argument to the realm of art production and artistic intention.

A crucial question for a renewed aesthetics is then: what follows from our inherence in history and culture? Insofar as history and culture play a considerable role in shaping our attitudes and interpretations of art and the world, the morms and standards we use in this regard are entirely conventional. Bound up, as they are, with the beliefs and practices of social groups at particular historical moments, they always carry prejudices and presuppositions.

It must be recognised, therefore, that debates in and about aesthetics cannot be conducted on the basis of purely neutral terms or grounds. As Julie Kuhlken argues in her paper, the appeal to aesthetics always also exposes the factors that limit our perspective, be they 'cultural, political, financial or simply practical.'

Here the position of Michel Foucault is of considerable value insofar as he provides the opportunity to reflect upon the notion that principles and norms are never entirely separable from the systems of knowledge/power that sustain them. Hence, reason and its modalities do not operate as a single unchanging principle but are always linked with systems of power (which produce and sustain them) and to effects of power (which they bring into existence). ${ }^{12}$

Aesthetics itself then must be viewed as part of what Foucault called, 'the political economy of truth.' As a result a central task aesthetic discourse must demand from itself is to show how artistic and aesthetic forms inscribe themselves in practices and systems, and to demonstrate what role they play within them. ${ }^{13}$

From the perspective that aesthetics may be linked to political and social issues in ways never envisaged by the canonical aesthetic theorists (which is by no means unique to Foucault) the debate may be conducted in two principal ways. Firstly in terms of an account of the rules and procedures within particular philosophical ideologies or styles (end-of-artism, phenomenology, hermeneutics, deconstruction, post-modernism, etc.). And secondly in questioning how the notion

\footnotetext{
${ }_{12}$ M. Foucault, Power/Knowledge: Selected Interviews and Other Writings 1972-1977, (Brighton, Harvester Press, 1980).

${ }^{13}$ M. Foucault, 'Questions of Method' in: Ideology and Consciousness, (8, 1981).
} 
of the aesthetic determines a realm of objects and experiences about which it is possible to express true or false propositions.

This moves aesthetics, in its various manifestations, away from both objective determination and post-modern irony to a perspective from which claims to truth and falsity are recognised as involving contextual criteria. From such a position the various applications of aesthetics may be in place to attempt to become aware of their own limits and historical situation. By doing so any general or universal claims they make will be recognised as linked to, and part of, the beliefs and practices of particular ways of life, world-views, philosophical theories, traditions and social systems.

Potentially the acknowledgement of the nature and limits of aesthetics, as it is interpreted and applied from different discursive positions, exposes deep ideological divisions between those different theoretical or stylistic approaches to the manner. The result of this would be that the force of the better argument is never available to decide between them in a neutral way, so that validity and evaluative criteria are acknowledged as the outcome of normalisation processes at work within particular theories or styles.

It is important to recognise that this view of aesthetics does not lead to an unproductive relativism or to the view that 'anything goes' as far as aesthetics is concerned. Rather, it recognises that aesthetic claims, explanations and theories involve various, often deep, institutional and cultural preconditions of a sort that rule out, or at least challenge, canonical conceptions of art, beauty, human experience, the aesthetic, etc. In addition, it does not follow necessarily that all significant claims made from the perspectives of different theories are radically incommensurable because cultural or institutional background may be at work in such a way that some choices may be made in terms of shared culturally determinate grounds.

Again, the question arises whether it is possible to progress to ever-better explanation and objectivity in terms of what Habermas called 'the force of the better argument,' or whether philosophy and aesthetics are internally fragmented in the sense that they embody a variety of viewpoints and practices which will continually elude full explanation and undermine objectivity (a question that might ultimately relate to how one views the Enlightenment project).

In whatever way one wishes to answer this question, we propose that a fruitful perspective on 
aesthetics must be understanding of differences among distinctive debates between (and within) disciplines. It also must be sensitive to the specific historical and social conditions of its own position. In this way, aesthetic theories will have a sense of their own limitations, be open to further interpretation by those who agree or disagree with them (in whole or in part), or be subject to radical challenge from those whose presuppositions and practices move them in a different direction. 